\title{
Plasma sex hormone concentrations and breast cancer risk in an ethnically diverse population of postmenopausal women: the Multiethnic Cohort Study
}

\author{
Christy G Woolcott, Yurii B Shvetsov, Frank Z Stanczyk ${ }^{1}$, Lynne R Wilkens, \\ Kami K White, Christian Caberto, Brian E Henderson ${ }^{1}$, Loïc Le Marchand, \\ Laurence N Kolonel and Marc T Goodman
}

\begin{abstract}
Epidemiology Program, Cancer Research Center of Hawaii, University of Hawaii, 1236 Lauhala Street, Honolulu, Hawaii 96813, USA ${ }^{1}$ Keck School of Medicine, University of Southern California, Los Angeles, California, USA

(Correspondence should be addressed to C G Woolcott; Email: cwoolcott@crch.hawaii.edu)
\end{abstract}

\begin{abstract}
To add to the existing evidence that comes mostly from White populations, we conducted a nested case-control study to examine the association between sex hormones and breast cancer risk within the Multiethnic Cohort that includes Japanese American, White, Native Hawaiian, African American, and Latina women. Of the postmenopausal women for whom we had a plasma sample, 132 developed breast cancer during follow-up. Two controls per case, matched on study area (Hawaii, Los Angeles), ethnicity/race, birth year, date and time of blood draw and time fasting, were randomly selected from the women who had not developed breast cancer. Levels of estradiol $\left(E_{2}\right)$, estrone $\left(E_{1}\right)$, androstenedione, dehydroepiandrosterone (DHEA), and testosterone were quantified by RIA after organic extraction and Celite column partition chromatography. $E_{1}$ sulfate, DHEA sulfate (DHEAS), and sex hormone-binding globulin (SHBG) were quantified by direct immunoassays. Based on conditional logistic regression, the sex hormones were positively associated and SHBG was negatively associated with breast cancer risk. All associations, except those with DHEAS and testosterone showed a significant linear trend. The odds ratio (OR) associated with a doubling of $\mathrm{E}_{2}$ levels was 2.26 (95\% confidence interval $\left.(\mathrm{Cl}) 1.58-3.25\right)$, and the $\mathrm{OR}$ associated with a doubling of testosterone levels was $1.34(95 \% \mathrm{Cl} 0.98-1.82)$. The associations in Japanese American women, who constituted $54 \%$ of our sample, were similar to or nonsignificantly stronger than in the overall group. This study provides the best evidence to date that the association between sex hormones and breast cancer risk is generalizable to an ethnically diverse population.
\end{abstract}

Endocrine-Related Cancer (2010) 17 125-134

\section{Introduction}

Many risk factors for postmenopausal breast cancer are thought to be mediated by a hormonal mechanism (Henderson \& Feigelson 2000, Clemons \& Goss 2001). The investigation of circulating sex hormones has provided evidence that is more direct. A pooled analysis published in 2002 (Key et al. 2002) of nine prospective studies of women not using hormone replacement therapy (HRT) found that all estrogenic and androgenic steroid sex hormones examined were associated with increased breast cancer risk, and that sex hormone-binding globulin (SHBG) was associated with decreased risk. Since the publication of this pooled analysis, these findings have been supported for the most part by analyses in some of the studies with extended follow-up (Missmer et al. 2004, Zeleniuch-Jacquotte et al. 2004, Cummings et al. 2005, Eliassen et al. 2006, Sieri et al. 2009) and additional large prospective studies (Cummings et al. 2002, Manjer et al. 2003, Onland-Moret et al. 2003, Kaaks et al. 2005, Beattie et al. 2006, Gunter et al. 2009). 
With a single exception, all of these studies were conducted in largely White populations. Kabuto et al. (2000) investigated the association of breast cancer with estradiol $\left(\mathrm{E}_{2}\right)$, SHBG, and dehydroepiandrosterone sulfate (DHEAS) in a prospective study of Japanese women in Japan, but had only 26 postmenopausal cases and did not investigate testosterone levels. The odds ratio (OR) for the association with a doubling of $\mathrm{E}_{2}$ levels was 0.90 (95\% confidence interval (CI) 0.42-1.92) (reported in Key et al. (2002)) suggesting that the association may be different in women of Japanese ancestry. Two case-control studies conducted in China, on the other hand, found that breast cancer risk in non-Japanese Asian postmenopausal women was positively associated with estrogen and testosterone levels (Yu et al. 2003, Wang et al. 2009). This report examines the association between estrogens $\left(E_{2}\right.$, estrone $\left(E_{1}\right)$, and $E_{1}$ sulfate), androgens (androstenedione, DHEA, DHEAS, and testosterone), and SHBG and breast cancer among postmenopausal women not using HRT within the Multiethnic Cohort (MEC) study. Because so few results are available from past studies in Asian populations, another objective was to examine these associations in the subgroup restricted to our Japanese American participants who comprise a large proportion of the MEC.

\section{Materials and methods}

\section{Study design and population}

We conducted a case-control study nested within the MEC. This cohort includes over 215000 men and women between the ages of 45 and 75 years at recruitment living in Hawaii and Los Angeles, California who returned a baseline questionnaire between 1993 and 1996 (Kolonel et al. 2000). From information in the questionnaire, participants were assigned to a single ethnic/racial group and if more than one group was reported, assignment was based on the following priority ranking: African American, Native Hawaiian, Latino, Japanese American, and White. More than $95 \%$ of all non-Hawaiians reported only one ethnic group. Body mass index (BMI) was calculated as weight divided by the square of height $\left(\mathrm{kg} / \mathrm{m}^{2}\right)$. Women were defined as postmenopausal if they reported cessation of menstrual periods naturally or due to bilateral oophorectomy, reported a hysterectomy without bilateral oophorectomy and use of HRT, or if this information was missing, were aged 55 years or older at blood draw.

Largely between 2001 and 2006, 67594 MEC participants agreed to donate a biospecimen and complete a short questionnaire that updated information including HRT use and menopausal status. Fasting blood was drawn in the early morning at a clinical laboratory or in the participant's home, processed, and separated into components. The plasma for the present hormone assays was stored in $2 \mathrm{ml}$ aliquots at $-80^{\circ} \mathrm{C}$. Some women only had serum available in our repository and were excluded because the volume of serum that could be extracted from the $0.5 \mathrm{ml}$ cryotubes in which it was stored was too low to reliably quantify the low hormone levels found in postmenopausal women. The MEC and this study were approved by the Institutional Review Boards of the University of Southern California and the University of Hawaii. All participants provided informed consent at the time of blood collection.

\section{Cases and controls}

Cases were women who had contributed a blood specimen before being diagnosed with a first primary breast cancer to the end of follow-up (December, 2006) and had plasma available for analysis. Diagnoses were identified by linkage of the MEC to the National Cancer Institute's Surveillance, Epidemiology, and End Results (SEER) program that covers the entire population of the Hawaii and California. Deaths were identified by linkage with state vital statistics databases and the National Death Index. Two control women per case were randomly selected from a pool of subcohort members who were alive and not diagnosed with breast cancer at the same age as the case at diagnosis, and matched to the case by area (Hawaii, Los Angeles), ethnicity, birth year ( \pm 1 year), date of blood draw ( \pm 6 months), time of blood draw $( \pm 2 \mathrm{~h}$ ), hours fasting before blood draw $(0-<6,6-<8,8-<10$, $\geq 10$ ), and HRT use at the time of blood draw. Only women not using HRT at the time of blood collection were included in this analysis.

Of the 326 cases who had a fasting blood sample available in the biorepository, 124 were currently using HRT and 70 had serum samples only. Thus, 132 incident breast cancer cases not using HRT had a plasma sample available for hormone measurement. Of the 264 controls matched to these cases, one did not have a plasma sample and two did not have sufficient sample for assays. Thus, a total of 132 cases and 261 controls had assay results for the analytes of primary interest (estrogens, testosterone, and DHEA). One control did not have sufficient sample to assay $E_{1}$ sulfate and DHEAS. 


\section{Laboratory assays}

Assays for sex hormones and SHBG were performed on plasma samples at the Reproductive Endocrine Research Laboratory at the University of Southern California (FZS). Each batch included matched casecontrol sets and pooled quality control samples, which were randomly ordered and were blinded to laboratory personnel, plus laboratory standards. Levels of the unconjugated steroid hormones were determined by RIA after organic extraction and partition chromatography on Celite columns (Goebelsmann et al. 1973, Stanczyk et al. 2007, 2009). Levels of $E_{1}$ sulfate were determined by direct immunoassay using kits from Beckman-Coulter Diagnostic Systems Laboratories (Webster, TX, USA; Ranadive et al. 1998). Levels of DHEAS and SHBG were determined using a chemiluminescent immunoassay on an Immulite analyzer (Siemens Medical Solutions USA Inc., Malvern, PA, USA). The limits of detection were $5 \mathrm{pg} / \mathrm{ml}$ for $\mathrm{E}_{1}$, $0.01 \mathrm{ng} / \mathrm{ml}$ for $E_{1}$ sulfate, $2 \mathrm{pg} / \mathrm{ml}$ for $E_{2}, 0.03 \mathrm{ng} / \mathrm{ml}$ for androstenedione, $0.04 \mathrm{ng} / \mathrm{ml}$ for DHEA, $15 \mu \mathrm{g} / \mathrm{dl}$ for DHEAS, $1.5 \mathrm{ng} / \mathrm{dl}$ for testosterone, and $1 \mathrm{nmol} / \mathrm{l}$ for SHBG. Seven women were below the limit for $E_{2}$ and 57 women were below the limit for DHEAS. These women were assumed to have levels equal to half of the detection limit. Bioavailable testosterone and $\mathrm{E}_{2}$ were estimated with a validated algorithm using the measured concentrations of the sex hormones and SHBG and an assumed albumin concentration of $43 \mathrm{~g} / \mathrm{l}$ (Sodergard et al. 1982, Vermeulen et al. 1999, Rinaldi et al. 2002). The intra-batch coefficients of variation (CV), based on 15 paired duplicates, were $10 \%$ for $\mathrm{E}_{1}$, $8.5 \%$ for $\mathrm{E}_{1}$ sulfate, $8.2 \%$ for $\mathrm{E}_{2}, 5.9 \%$ for androstenedione, $3.9 \%$ for DHEA, $4.6 \%$ for DHEAS, $4.2 \%$ for testosterone, and $7.5 \%$ for SHBG.

\section{Statistical analysis}

ORs for the association between breast cancer risk and hormone concentration in quartiles based on the distribution in controls were computed using

Table 1 Characteristics of the cases and controls

\begin{tabular}{|c|c|c|c|c|}
\hline \multirow[b]{2}{*}{ Characteristic } & \multicolumn{2}{|c|}{ All women } & \multicolumn{2}{|c|}{ Japanese American } \\
\hline & $\begin{array}{c}\text { Cases } \\
N(\%)\end{array}$ & $\begin{array}{c}\text { Controls } \\
N(\%)\end{array}$ & $\begin{array}{c}\text { Cases } \\
N(\%)\end{array}$ & $\begin{array}{c}\text { Controls } \\
N(\%)\end{array}$ \\
\hline Number of subjects & $132(100)$ & $261(100)$ & $72(100)$ & $142(100)$ \\
\hline \multicolumn{5}{|l|}{ Ethnicity/race $\mathrm{a}^{\mathrm{a}}$} \\
\hline Japanese American & $72(54.5)$ & $142(54.4)$ & $72(100)$ & $142(100)$ \\
\hline White & $30(22.7)$ & $60(23.0)$ & $0(0)$ & $0(0)$ \\
\hline Native Hawaiian & 17 (12.9) & $34(13.0)$ & $0(0)$ & $0(0)$ \\
\hline African American & $8(6.1)$ & $15(5.7)$ & $0(0)$ & $0(0)$ \\
\hline Latina & $5(3.8)$ & $10(3.8)$ & $0(0)$ & $0(0)$ \\
\hline \multicolumn{5}{|l|}{ Number of children ${ }^{b}$} \\
\hline 0 & 17 (12.9) & $28(10.8)$ & $6(8.3)$ & $11(7.7)$ \\
\hline 1 & $7(5.3)$ & $24(9.2)$ & $4(5.6)$ & $17(12.0)$ \\
\hline $2-3$ & $70(53.0)$ & $134(51.5)$ & $45(62.5)$ & $86(60.6)$ \\
\hline$\geq 4$ & $38(28.8)$ & $74(28.5)$ & $17(23.6)$ & $27(19.0)$ \\
\hline Aged $\geq 25$ years at first birth, parous women ${ }^{b}$ & $40(34.8)$ & $65(28.0)$ & $28(42.4)$ & $50(38.5)$ \\
\hline Residence in Hawaii ${ }^{\mathrm{a}}$ & $113(85.6)$ & $224(85.8)$ & $66(91.7)$ & $130(91.5)$ \\
\hline$>12$ years of education ${ }^{b}$ & $91(68.5)$ & $172(65.9)$ & $52(72.2)$ & $101(71.1)$ \\
\hline Menarche at $<13$ years of age ${ }^{b}$ & $70(53.8)$ & $145(56.4)$ & $40(55.6)$ & $79(55.6)$ \\
\hline Past oral contraceptive use & $67(50.8)$ & $119(45.6)$ & $32(44.4)$ & $60(42.3)$ \\
\hline Past use of $\mathrm{HRT}^{\mathrm{b}}$ & $68(52.7)$ & $132(51.2)$ & $37(51.4)$ & $71(50.0)$ \\
\hline First degree family history of breast cancer & $10(7.6)$ & $34(13.0)$ & $5(6.9)$ & $16(11.3)$ \\
\hline \multirow[t]{2}{*}{ Consumed $\geq 1$ alcoholic drink/day at baseline } & $12(9.1)$ & $23(8.8)$ & $1(1.4)$ & $3(2.1)$ \\
\hline & Median (IQR) & Median (IQR) & Median (IQR) & Median (IQR) \\
\hline Age at blood draw ${ }^{a}$ (years) & $68.0(61.4-75.7)$ & $68.1(61.2-75.2)$ & $67.7(62.7-74.0)$ & $67.6(62.0-73.4)$ \\
\hline Years between blood draw and case diagnosis ${ }^{a}$ & $0.9(0.5-1.9)$ & $1.0(0.5-1.9)$ & $1.3(0.6-2.3)$ & $1.3(0.6-2.3)$ \\
\hline Years between baseline and blood draw & $9.2(8.6-10.4)$ & $9.4(8.9-10.4)$ & $9.0(8.5-10.4)$ & $9.3(8.8-10.1)$ \\
\hline Hours fasting before blood draw ${ }^{a}$ & $13.1(12.0-14.1)$ & $12.9(11.8-14.1)$ & $13.3(12.0-14.1)$ & $13.1(11.8-14.0)$ \\
\hline Body mass index at baseline ${ }^{b}\left(\mathrm{~kg} / \mathrm{m}^{2}\right)$ & $24.7(22.4-27.6)$ & $24.0(21.5-27.5)$ & $24.0(21.5-26.7)$ & $23.2(20.9-25.8)$ \\
\hline Physical activity at baseline ${ }^{\mathrm{b}}$ (MET-hours/week) & $4.2(1.4-8.9)$ & $3.6(2.0-8.2)$ & $4.8(1.4-8.9)$ & $3.6(2.0-8.0)$ \\
\hline
\end{tabular}

HRT, hormone replacement therapy; IQR, interquartile range (25th to 75th percentile); MET, metabolic equivalent. a Matching variables.

${ }^{b}$ Summary statistics based on slightly fewer than the total $N$ in each group due to missing values. 
conditional logistic regression with the matched sets as strata. Because levels of hormones and SHBG were positively skewed, they were logarithmically (base 2) transformed when used as continuous variables as was done in the pooled analysis (Key et al. 2002). The corresponding ORs represent the risk associated with a doubling of hormone concentration; these analyses also constituted our test for trend. Included in the models were two of the matching factors as continuous variables, age at blood draw and hours fasting, to control for any residual differences in these variables between cases and matched controls. We also evaluated a number of risk factors as potential confounders (listed in Table 1). None was retained as a confounder because when added to the models, they changed the ORs associated with a doubling of hormone concentration no more than 10\% (Mickey \& Greenland 1989). Analyses stratified by HRT use (past, never) and time between blood collection and diagnosis of the case in the set ( $<1, \geq 1$ year) were done. These analyses used hormone levels as continuous variables; the product between the stratification variable and hormone variables was introduced into the models to assess the significance of any effect modification. An analysis stratified by ethnicity, using hormone levels as continuous variables, compared Japanese American women to the group of women of other ethnicities/ races combined. We did not have a sufficient number of women in any other single ethnic/racial group to compare directly to the group of Japanese American women. The analyses were done using SAS version 9.1 (SAS Institute, Cary, NC, USA). All statistical tests were two-sided with a 0.05 level of significance.

\section{Results}

Characteristics of all women (132 cases and 261 controls) and the subgroup of Japanese American women (72 cases and 142 controls) are shown in Table 1. The median age of all participants was 68 years, and over half of the women were Japanese American. About half of both cases and controls used HRT in the past. Levels of the sex hormones were uniformly higher in cases than controls, whereas the level of SHBG was lower in cases than controls (Table 2). Among controls, levels of the analytes were often significantly correlated. For example, the Pearson correlations (using log-transformed values) of $\mathrm{E}_{2}$ with $\mathrm{E}_{1}$, testosterone, and SHBG were $0.51,0.33$, and -0.27 respectively (all $P<0.05$ ). Among controls, the geometric mean $\mathrm{E}_{2}$ concentration adjusted for age and BMI varied significantly among the ethnic/racial groups $(P=0.03)$, with African American women having high average levels (39 pmol/l) and Latinas having low average levels $(20 \mathrm{pmol} / \mathrm{l})$ relative to the other three groups $(28 \mathrm{pmol} / \mathrm{l})$.

Sex hormones were positively associated with breast cancer risk, and SHBG was inversely associated with breast cancer risk (Fig. 1). All associations, except those with DHEAS and testosterone, showed a significant trend, the strongest of which were observed for $E_{2}$ and free $E_{2}$. Women who had $E_{2}$ levels in the highest quartile had over sixfold increased risk of breast cancer relative to women in the lowest quartile (OR 6.43, 95\% CI 2.78-14.9). We did not find that past HRT use significantly modified any of these associations (all $P$ for heterogeneity $>0.05$ ). Generally, the trends observed in the overall group were reflected in both past and never users of HRT but were larger in magnitude among the former group (data not shown). The ORs for the associations between a doubling of estrogen levels and breast cancer risk were slightly, but nonsignificantly, greater if blood was taken 1 year or more before diagnosis whereas the OR for the association between SHBG and breast cancer risk

Table 2 Geometric mean (95\% confidence interval) concentrations of sex hormones and SHBG in cases and controls

\begin{tabular}{|c|c|c|c|c|}
\hline \multirow[b]{2}{*}{ Sex hormone/SHBG } & \multicolumn{2}{|c|}{ All women } & \multicolumn{2}{|c|}{ Japanese American } \\
\hline & Cases & Controls & Cases & Controls \\
\hline SHBG (nmol/l) & $38(35-41)$ & $44(41-47)$ & $35(31-40)$ & $43(39-48)$ \\
\hline Estrone (pmol/l) & $132(122-143)$ & $112(106-118)$ & $128(115-143)$ & $108(100-116)$ \\
\hline Estrone sulfate (pmol/l) & $1363(1218-1525)$ & $1168(1092-1250)$ & $1548(1372-1748)$ & $1295(1189-1410)$ \\
\hline Estradiol (pmol/l) & $37(33-41)$ & $28(26-30)$ & $36(32-41)$ & $28(25-30)$ \\
\hline Free estradiol (pmol/l) & $0.96(0.87-1.07)$ & $0.70(0.64-0.76)$ & $0.96(0.83-1.10)$ & $0.68(0.61-0.75)$ \\
\hline Androstenedione (nmol/l) & 2.02 (1.87-2.19) & $1.73(1.63-1.84)$ & 1.99 (1.79-2.21) & $1.66(1.54-1.79)$ \\
\hline DHEA (nmol/l) & $7.61(6.82-8.49)$ & $6.30(5.79-6.86)$ & $8.20(7.15-9.41)$ & $6.72(6.07-7.43)$ \\
\hline DHEAS (nmol/l) & 1068 (927-1229) & $916(825-1018)$ & $1217(1024-1447)$ & 1071 (931-1231) \\
\hline Testosterone $(\mathrm{nmol} / \mathrm{l})$ & $0.83(0.76-0.90)$ & $0.75(0.71-0.80)$ & $0.77(0.70-0.86)$ & $0.71(0.66-0.77)$ \\
\hline Free testosterone $(\mathrm{pmol} / \mathrm{l})$ & $17.2(15.9-18.6)$ & $14.4(13.5-15.3)$ & $16.6(15.1-18.2)$ & $13.6(12.42-14.8)$ \\
\hline
\end{tabular}

DHEA, dehydroepiandrosterone; DHEAS, dehydroepiandrosterone sulfate; SHBG, sex hormone-binding globulin. 


\begin{tabular}{|c|c|c|c|c|c|c|}
\hline Hormone & Cases & Controls & $\mathrm{OR}^{\mathrm{a}}(95 \% \mathrm{CI})$ by & y quartile of hormones & $\begin{array}{c}\mathrm{OR}^{\mathrm{a}}(95 \% \mathrm{CI}) \\
\text { per doubling }\end{array}$ & $P_{\text {trend }}$ \\
\hline \multicolumn{7}{|l|}{ SHBG } \\
\hline$\leq 29 \mathrm{nmol} / \mathrm{L}$ & 37 & 64 & 1.00 & 1) & & \\
\hline$>29-45$ & 49 & 67 & $1.33(0.75-2.37)$ & $+\square$ & & \\
\hline$>45-65$ & 31 & 65 & $0.79(0.42-1.49)$ & $\square$ & & \\
\hline$>65$ & 15 & 65 & $0.35(0.17-0.73)$ & & $0.66(0.49-0.88)$ & 0.006 \\
\hline \multicolumn{7}{|l|}{ Estrone } \\
\hline$\leq 86 \mathrm{pmol} / \mathrm{L}$ & 21 & 65 & 1.00 & 自 & & \\
\hline$>86-113$ & 29 & 66 & $1.37(0.71-2.64)$ & $\square$ & & \\
\hline$>113-157$ & 38 & 64 & $1.99(1.02-3.88)$ & $\square \square$ & & \\
\hline$>157$ & 44 & 66 & $2.17(1.13-4.17)$ & $\square$ & $1.83(1.28-2.61)$ & 0.001 \\
\hline \multicolumn{7}{|l|}{ Estrone sulfate } \\
\hline$\leq 874 \mathrm{pmol} / \mathrm{L}$ & 24 & 66 & 1.00 & 自 & & \\
\hline$>874-1256$ & 28 & 67 & $1.79(0.80-3.99)$ & $\square$ & & \\
\hline$>1256-1720$ & 31 & 65 & $2.15(0.93-4.97)$ & $\square \square$ & & \\
\hline$>1720$ & 49 & 62 & $4.24(1.75-10.3)$ & $\square$ & $1.81(1.24-2.64)$ & 0.002 \\
\hline \multicolumn{7}{|l|}{ Estradiol } \\
\hline$\leq 21 \mathrm{pmol} / \mathrm{L}$ & 17 & 66 & 1.00 & 自 & & \\
\hline$>21-31$ & 31 & 65 & $2.68(1.22-5.89)$ & $\square \square$ & & \\
\hline$>31-40$ & 21 & 65 & $2.02(0.82-4.97)$ & $\square$ & & \\
\hline$>40$ & 63 & 65 & $6.43(2.78-14.9)$ & $\square$ & $2.26(1.58-3.25)$ & $<0.001$ \\
\hline \multicolumn{7}{|l|}{ Free estradiol } \\
\hline$\leq 0.46 \mathrm{pmol} / \mathrm{L}$ & 15 & 65 & 1.00 & 目 & & \\
\hline$>0.46-0.75$ & 32 & 65 & $2.60(1.24-5.48)$ & $\square \square$ & & \\
\hline$>0.75-1.05$ & 25 & 66 & $2.61(1.10-6.21)$ & $\longrightarrow$ & & \\
\hline$>1.05$ & 60 & 65 & $6.78(2.93-15.7)$ & $\longrightarrow$ & $2.26(1.62-3.15)$ & $<0.001$ \\
\hline \multicolumn{7}{|l|}{ Androstenedione } \\
\hline$\leq 1.32 \mathrm{nmol} / \mathrm{L}$ & 23 & 66 & 1.00 & 目 & & \\
\hline$>1.32-1.74$ & 27 & 64 & $1.28(0.65-2.51)$ & $\square$ & & \\
\hline$>1.71-2.33$ & 33 & 66 & $1.48(0.77-2.82)$ & $+\square$ & & \\
\hline$>2.33$ & 49 & 65 & $2.31(1.23-4.34)$ & $\longrightarrow$ & $1.62(1.18-2.23)$ & 0.003 \\
\hline \multicolumn{7}{|l|}{ DHEA } \\
\hline$\leq 4.24 \mathrm{nmol} / \mathrm{L}$ & 22 & 66 & 1.00 & 1) & & \\
\hline$>4.24-6.63$ & 36 & 65 & $1.72(0.89-3.32)$ & $\square$ & & \\
\hline$>6.63-10.96$ & 33 & 64 & $1.71(0.86-3.38)$ & $+\square$ & & \\
\hline$>10.96$ & 41 & 66 & $1.97(1.01-3.82)$ & $\square$ & $1.38(1.09-1.75)$ & 0.008 \\
\hline \multicolumn{7}{|l|}{ DHEAS } \\
\hline$\leq 534 \mathrm{nmol} / \mathrm{L}$ & 21 & 66 & 1.00 & 1 & & \\
\hline$>534-1003$ & 35 & 64 & $1.94(0.96-3.90)$ & $\square$ & & \\
\hline$>1003-1764$ & 42 & 65 & $2.25(1.14-4.42)$ & $\longrightarrow$ & & \\
\hline$>1764$ & 34 & 65 & $1.90(0.93-3.89)$ & 口- & $1.20(0.99-1.46)$ & 0.06 \\
\hline \multicolumn{7}{|l|}{ Testosterone } \\
\hline$\leq 0.56 \mathrm{nmol} / \mathrm{L}$ & 33 & 66 & 1.00 & tid & & \\
\hline$>0.56-0.75$ & 30 & 65 & $0.92(0.48-1.76)$ & $-\square$ & & \\
\hline$>0.75-0.99$ & 19 & 65 & $0.58(0.30-1.14)$ & 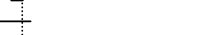 & & \\
\hline$>0.99$ & 50 & 65 & $1.57(0.88-2.80)$ & 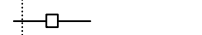 & $1.34(0.98-1.82)$ & 0.07 \\
\hline \multicolumn{7}{|l|}{ Free testosterone } \\
\hline$\leq 10.2 \mathrm{pmol} / \mathrm{L}$ & 18 & 65 & 1.00 & 1. & & \\
\hline$>10.2-14.7$ & 31 & 65 & $1.74(0.88-3.48)$ & $\square$ & & \\
\hline$>14.7-20.0$ & 31 & 66 & $1.74(0.88-3.43)$ & $\square$ & & \\
\hline \multirow[t]{2}{*}{$>20.0$} & 52 & 65 & $3.18(1.63-6.21)$ & $\longrightarrow$ & $1.71(1.25-2.34)$ & 0.001 \\
\hline & & & 0.5 & 10 & & \\
\hline
\end{tabular}

Figure 1 Odds ratios $(\mathrm{OR})$ and $95 \%$ confidence intervals $(\mathrm{Cl})$ for the association of hormone concentrations with the risk of breast cancer. ${ }^{\mathrm{a} C}$ Cases and controls were matched on area, ethnicity, birth year ( \pm 1 year), date of blood draw ( \pm 6 months), time of blood draw and hours fasting (in categories), and ORs were additionally adjusted for age at blood draw and hours fasting as continuous variables.

was slightly, but nonsignificantly, more protective if blood was taken $<1$ year before diagnosis (data not shown). As depicted in Fig. 2, when the analysis was restricted to Japanese American women, all associations except those with DHEAS and testosterone showed a significant trend and were nonsignificantly stronger than the associations in women of other ethnicity/race (all $P$ for heterogeneity $>0.05$ ). For example, the OR for a doubling of $E_{2}$ was 2.88 (95\% CI 1.63-5.10) in Japanese American women as compared to 1.87 (95\% CI 1.17-2.99) in women of other ethnicity/race.

\section{Discussion}

In this study, estrogenic and androgenic hormones were positively associated, and SHBG was inversely associated with breast cancer risk. The pooled analysis done in 2002 (Key et al. 2002) and four prospective studies of circulating hormones done since then (Cummings et al. 2002, Manjer et al. 2003, Kaaks et al. 2005, Gunter et al. 2009) have also found such associations although a fifth prospective study did not (Beattie et al. 2006). In the current study, stronger associations than in other prospective studies were observed for some analytes such as $E_{2}, E_{1}$ sulfate, 


\begin{tabular}{|c|c|c|c|c|c|}
\hline Hormone & Group & OR $(95 \% \mathrm{CI})$ & & & $P_{\text {trend }}$ \\
\hline \multirow[t]{2}{*}{ SHBG } & Japanese & $0.59(0.40-0.87)$ & $\square$ & & 0.01 \\
\hline & Other & $0.77(0.48-1.25)$ & $\square \square$ & & 0.29 \\
\hline \multirow[t]{2}{*}{ Estrone } & Japanese & $1.98(1.20-3.24)$ & & $\longrightarrow \square$ & 0.01 \\
\hline & Other & $1.68(1.01-2.81)$ & & $\square$ & 0.05 \\
\hline \multirow[t]{2}{*}{ Estrone sulfate } & Japanese & $2.33(1.30-4.18)$ & & $\square \square$ & 0.01 \\
\hline & Other & $1.49(0.91-2.44)$ & & $\square$ & 0.12 \\
\hline \multirow[t]{2}{*}{ Estradiol } & Japanese & $2.88(1.63-5.10)$ & & $\longrightarrow \square-$ & $<0.001$ \\
\hline & Other & $1.87(1.17-2.99)$ & & $\longrightarrow \square-$ & 0.01 \\
\hline \multirow[t]{2}{*}{ Free estradiol } & Japanese & $2.78(1.68-4.62)$ & & $\square \square$ & $<0.001$ \\
\hline & Other & $1.87(1.20-2.91)$ & & $\square$ & 0.01 \\
\hline \multirow[t]{2}{*}{ Androstenedione } & Japanese & $1.95(1.21-3.15)$ & & $\longrightarrow \square$ & 0.01 \\
\hline & Other & $1.38(0.90-2.12)$ & & $-\square-$ & 0.14 \\
\hline \multirow[t]{2}{*}{ DHEA } & Japanese & $1.53(1.07-2.20)$ & & $\square$ & 0.02 \\
\hline & Other & $1.27(0.92-1.74)$ & & $\square-$ & 0.15 \\
\hline \multirow[t]{2}{*}{ DHEAS } & Japanese & $1.17(0.90-1.53)$ & & $\square-$ & 0.23 \\
\hline & Other & $1.23(0.92-1.64)$ & & $-\square$ & 0.16 \\
\hline \multirow[t]{2}{*}{ Testosterone } & Japanese & $1.34(0.87-2.08)$ & & $\square$ & 0.19 \\
\hline & Other & $1.33(0.85-2.08)$ & & $\square$ & 0.21 \\
\hline \multirow[t]{3}{*}{ Free testosterone } & Japanese & $2.01(1.25-3.22)$ & & $\square \square$ & 0.004 \\
\hline & Other & $1.49(0.97-2.31)$ & & $-\square-$ & 0.07 \\
\hline & & & 0.5 & 2 & \\
\hline
\end{tabular}

Figure 2 Odds ratios (OR) and 95\% confidence intervals $(\mathrm{Cl})$ for the association between a doubling of hormone concentrations and the risk of breast cancer among Japanese American women and women of other race/ethnicity. ${ }^{\mathrm{a}} \mathrm{Cases}$ and controls were matched on area, ethnicity, birth year ( \pm 1 year), date of blood draw ( \pm 6 months), time of blood draw and hours fasting (in categories), and ORs were additionally adjusted for age at blood draw and hours fasting as continuous variables.

and SHBG. For example, the OR for a doubling of $\mathrm{E}_{2}$ concentration was 2.26 (95\% CI 1.58-3.25), whereas in the pooled analysis, it was 1.29 (95\% CI 1.15-1.44) with ORs ranging from 0.76 to 1.69 in the individual studies.

The impact of the short time between blood collection and diagnosis (median of 1 year), which could be construed as a limitation of our study, should be considered. Because mammary tumors express aromatase, they have the capability of producing estrogens from androgens (Pasqualini et al. 1996), and if the estrogens thus produced enter the circulation, reverse causality could be a concern. However, in breast cancer patients, breast tissue estrogens do not reflect circulating estrogens (Geisler 2003). Furthermore, in one study that collected two blood samples a mean of 31 months apart, the rate of change in most hormone levels was not significantly different between cases and controls, suggesting that the presence of an undetected tumor does not have a large effect on circulating hormone levels (Zeleniuch-Jacquotte et al. 2004).
The second sample, however, was collected on average 28 months before the diagnosis of the case, and the possibility still remains that tumors closer than this to diagnosis have an effect on circulating hormone levels. Additional information about the impact of the time between blood collection and diagnosis comes from prospective studies that have stratified on this factor, which had little effect on most associations (Dorgan et al. 1996, Zeleniuch-Jacquotte et al. 1997, Hankinson et al. 1998, Kabuto et al. 2000, Key et al. 2002, Sieri et al. 2009). Associations between a few of the hormones and breast cancer risk, however, were weaker (Toniolo et al. 1995, Dorgan et al. 1997, Hankinson et al. 1998, Onland-Moret et al. 2003) or stronger (Dorgan et al. 1996, Kabuto et al. 2000, ZeleniuchJacquotte et al. 2004) with less time between blood collection and diagnosis.

The strength of the association observed for circulating estrogen concentrations with breast cancer risk was notable in our multiethnic population. Some of these associations may have been stronger than in 
other prospective studies because our indirect assays have been shown to have high validity and reliability (Lee et al. 2006), perhaps leading to less attenuation of risk estimates due to nondifferential exposure misclassification. $E_{2}$ measurements done in the laboratory in which our assays were performed correlate very well with the gold standard method gas chromatography tandem mass spectrometry (GC-MS/MS), whereas direct assays without an extraction step that reduces cross-reactivity with other hormone metabolites correlate less well (Lee et al. 2006). The CV of the assays done in this study, however, are not noticeably lower than those reported in other studies where case-control sets were placed in the same batch to eliminate the effect of inter-batch variability (Tworoger \& Hankinson 2006). Also possibly contributing to the strength of our associations is the fact that Japanese American women comprised over half of our sample in whom the associations between most sex hormones and breast cancer risk appeared to be of greater magnitude than in women of other ethnicity/race. This difference, however, would not be enough to wholly explain our stronger results for $E_{1}, E_{2}$, and SHBG in comparison to previous prospective studies.

The only other prospective study done among postmenopausal Asian women, conducted in Japan, found no significant association between breast cancer risk and total $\mathrm{E}_{2}$, bioavailable $\mathrm{E}_{2}$, DHEAS, and SHBG; the point estimate for $\mathrm{E}_{2}$ was below 1.0 but the $95 \%$ CIs were wide due to a small sample size (Kabuto et al. 2000). Two case-control studies conducted in China, however, found positive associations between postmenopausal breast cancer risk and levels of estrogens and testosterone (Yu et al. 2003, Wang et al. 2009). The Japanese American women in the current study may have had higher levels of sex hormones than the Asian women in the other studies: higher sex hormone levels have been observed in Western Japanese as compared to Eastern Japanese populations in studies using the same assay techniques (Shimizu et al. 1990). Although this appears to be contradicted by the reported median or geometric mean $\mathrm{E}_{2}$ concentration being higher in the controls of two of these studies (Kabuto et al. 2000, Wang et al. 2009) than in the current study, comparing levels across studies is not possible when assay techniques are different (Key et al. 2002).

In the MEC, Japanese American women are at similar or slightly higher risk of breast cancer relative to White women (Pike et al. 2002, Woolcott et al. 2009). This result is compatible with observations made in the current study population and another within the MEC (Setiawan et al. 2006) that Japanese
American women have sex hormone levels similar to or slightly higher than White women once age, BMI, and other factors are taken into account. Postmenopausal Japanese American women in the MEC, of whom $89 \%$ were born in the United States, may lead a fairly westernized lifestyle and thus may have a distribution similar to White women of lifestyle factors that affect sex hormone concentration. For example, indicators of a westernized diet, such as low vegetable and soy intake, are associated with lower SHBG concentrations (Wu et al. 2009) and higher testosterone concentrations (Setiawan et al. 2006). With respect to dietary patterns, however, Japanese Americans in the MEC are still likely to differ somewhat from Whites (Park et al. 2005).

In this study, we had sufficient statistical power with the whole sample to detect associations of the magnitude observed in other prospective studies of circulating hormones and breast cancer risk but our ability to detect differences in effect among subgroups was limited by our sample size. We had a larger number of women of Asian ancestry than in other published prospective studies, and we found significant associations in this group. Because the other ethnic/ racial groups each had few subjects, we compared the results in the Japanese American women to those in the other groups combined. As follow-up continues, we will be able to pursue analyses by each ethnic/ racial group separately. Although we relied on a single blood draw for our analysis, other studies have observed that hormone levels up to 5 years apart are moderately correlated suggesting that a single hormone measurement adequately characterizes levels over a longer period of time (Toniolo et al. 1995, Kim \& Zeleniuch-Jacquotte 1997, Hankinson et al. 1998, Zeleniuch-Jacquotte et al. 2004). Our covariate information was largely derived from the baseline questionnaire, which was done an average of 9.3 years before the blood was drawn. This limitation only applies to time-dependent covariates, such as BMI, which are unlikely to change the conclusions in this study because in most other studies, covariates confound the associations between circulating sex hormones and breast cancer risk very little (Dorgan et al. 1996, Hankinson et al. 1998, Kabuto et al. 2000, Key et al. 2002, Endogenous Hormones and Breast Cancer Collaborative Group 2003, Onland-Moret et al. 2003, Zeleniuch-Jacquotte et al. 2004, Cummings et al. 2005, Kaaks et al. 2005).

In conclusion, this study supports previous evidence that sex hormone levels are associated with an increased risk of breast cancer, and SHBG levels are associated with a decreased risk among 
postmenopausal women. It demonstrates that these associations are generalizable to an ethnically diverse population, and furthermore, it suggests that these associations remain similar when restricted to Japanese American women.

\section{Declaration of interest}

The authors declare that there is no conflict of interest that could be perceived as prejudicing the impartiality of the research reported.

\section{Funding}

This work was supported in part by National Cancer Institute (grants P01 CA33619 and R37 CA54281), and by the National Institutes of Health, Department of Health and Human Services (contracts N01-PC-35137 and N01-PC35139). C G Woolcott was supported by a postdoctoral fellowship on grant R25 CA90956.

\section{Author contribution statement}

C G Woolcott carried out the statistical analysis, interpreted the results, and wrote the manuscript. L R Wilkens and M T Goodman also helped to interpret the results. Y B Shvetsov and L R Wilkens provided statistical expertise. K K White and $\mathrm{C}$ Caberto were involved in data acquisition, management, and subject selection. B E Henderson and L N Kolonel are the Principal Investigators of the Multiethnic Cohort Study and with M T Goodman, L R Wilkens, and L Le Marchand were involved in the concept and procurement of funding for this particular project. F Z Stanczyk carried out the hormone assays and helped to interpret this data. All authors provided feedback on the initial draft of the manuscript and approved the final manuscript.

\section{Acknowledgements}

We thank Anne Tome for database management, and all participants and staff involved in the study.

\section{References}

Beattie MS, Costantino JP, Cummings SR, Wickerham DL, Vogel VG, Dowsett M, Folkerd EJ, Willett WC, Wolmark N \& Hankinson SE 2006 Endogenous sex hormones, breast cancer risk, and tamoxifen response: an ancillary study in the NSABP Breast Cancer Prevention Trial (P-1). Journal of the National Cancer Institute 98 110-115.

Clemons M \& Goss P 2001 Estrogen and the risk of breast cancer. New England Journal of Medicine 344 276-285.

Cummings SR, Duong T, Kenyon E, Cauley JA, Whitehead M \& Krueger KA 2002 Serum estradiol level and risk of breast cancer during treatment with raloxifene. Journal of the American Medical Association 287 216-220.
Cummings SR, Lee JS, Lui LY, Stone K, Ljung BM \& Cauleys JA 2005 Sex hormones, risk factors, and risk of estrogen receptor-positive breast cancer in older women: a long-term prospective study. Cancer Epidemiology, Biomarkers and Prevention 14 1047-1051.

Dorgan JF, Longcope C, Stephenson HE, Falk RT, Miller R, Franz C, Kahle L, Campbell WS, Tangrea JA \& Schatzkin A 1996 Relation of prediagnostic serum estrogen and androgen levels to breast cancer risk. Cancer Epidemiology, Biomarkers and Prevention 5 533-539.

Dorgan JF, Stanczyk FZ, Longcope C, Stephenson HE, Chang L, Miller R, Franz C, Falk RT \& Kahle L 1997 Relationship of serum dehydroepiandrosterone (DHEA), DHEA sulfate, and 5-androstene-3 $\beta, 17 \beta$-diol to risk of breast cancer in postmenopausal women. Cancer Epidemiology, Biomarkers and Prevention 6 177-181.

Eliassen AH, Missmer SA, Tworoger SS \& Hankinson SE 2006 Endogenous steroid hormone concentrations and risk of breast cancer: does the association vary by a woman's predicted breast cancer risk? Journal of Clinical Oncology 24 1823-1830.

Endogenous Hormones and Breast Cancer Collaborative Group 2003 Body mass index, serum sex hormones, and breast cancer risk in postmenopausal women. Journal of the National Cancer Institute 95 1218-1226.

Geisler J 2003 Breast cancer tissue estrogens and their manipulation with aromatase inhibitors and inactivators. Journal of Steroid Biochemistry and Molecular Biology 86 245-253.

Goebelsmann U, Horton R, Mestman JH, Arce JJ, Nagata Y, Nakamura RM, Thorneycroft IH \& Mishell DR Jr 1973 Male pseudohermaphroditism due to testicular 17-hydroxysteroid dehydrogenase deficiency. Journal of Clinical Endocrinology and Metabolism 36 867-879.

Gunter MJ, Hoover DR, Yu H, Wassertheil-Smoller S, Rohan TE, Manson JE, Li J, Ho GY, Xue X, Anderson GL et al. 2009 Insulin, insulin-like growth factor-I, and risk of breast cancer in postmenopausal women. Journal of the National Cancer Institute 101 48-60.

Hankinson SE, Willett WC, Manson JE, Colditz GA, Hunter DJ, Spiegelman D, Barbieri RL \& Speizer FE 1998 Plasma sex steroid hormone levels and risk of breast cancer in postmenopausal women. Journal of the National Cancer Institute 90 1292-1299.

Henderson BE \& Feigelson HS 2000 Hormonal carcinogenesis. Carcinogenesis 21 427-433.

Kaaks R, Rinaldi S, Key TJ, Berrino F, Peeters PH, Biessy C, Dossus L, Lukanova A, Bingham S, Khaw KT et al. 2005 Postmenopausal serum androgens, oestrogens and breast cancer risk: the European prospective investigation into cancer and nutrition. Endocrine-Related Cancer 12 1071-1082.

Kabuto M, Akiba S, Stevens RG, Neriishi K \& Land CE 2000 A prospective study of estradiol and breast cancer in Japanese women. Cancer Epidemiology, Biomarkers and Prevention 9 575-579. 
Key T, Appleby P, Barnes I \& Reeves G 2002 Endogenous sex hormones and breast cancer in postmenopausal women: reanalysis of nine prospective studies. Journal of the National Cancer Institute 94 606-616.

Kim MY \& Zeleniuch-Jacquotte A 1997 Correcting for measurement error in the analysis of case-control data with repeated measurements of exposure. American Journal of Epidemiology 145 1003-1010.

Kolonel LN, Henderson BE, Hankin JH, Nomura AM, Wilkens LR, Pike MC, Stram DO, Monroe KR, Earle ME \& Nagamine FS 2000 A multiethnic cohort in Hawaii and Los Angeles: baseline characteristics. American Journal of Epidemiology 151 346-357.

Lee JS, Ettinger B, Stanczyk FZ, Vittinghoff E, Hanes V, Cauley JA, Chandler W, Settlage J, Beattie MS, Folkerd E et al. 2006 Comparison of methods to measure low serum estradiol levels in postmenopausal women. Journal of Clinical Endocrinology and Metabolism 91 3791-3797.

Manjer J, Johansson R, Berglund G, Janzon L, Kaaks R, Agren A \& Lenner P 2003 Postmenopausal breast cancer risk in relation to sex steroid hormones, prolactin and SHBG (Sweden). Cancer Causes and Control 14 599-607.

Mickey RM \& Greenland S 1989 The impact of confounder selection criteria on effect estimation. American Journal of Epidemiology 129 125-137.

Missmer SA, Eliassen AH, Barbieri RL \& Hankinson SE 2004 Endogenous estrogen, androgen, and progesterone concentrations and breast cancer risk among postmenopausal women. Journal of the National Cancer Institute 96 1856-1865.

Onland-Moret NC, Kaaks R, van Noord PA, Rinaldi S, Key T, Grobbee DE \& Peeters PH 2003 Urinary endogenous sex hormone levels and the risk of postmenopausal breast cancer. British Journal of Cancer 88 1394-1399.

Park SY, Murphy SP, Wilkens LR, Yamamoto JF, Sharma S, Hankin JH, Henderson BE \& Kolonel LN 2005 Dietary patterns using the Food Guide Pyramid groups are associated with sociodemographic and lifestyle factors: the multiethnic cohort study. Journal of Nutrition 135 843-849.

Pasqualini JR, Chetrite G, Blacker C, Feinstein MC, Delalonde L, Talbi M \& Maloche C 1996 Concentrations of estrone, estradiol, and estrone sulfate and evaluation of sulfatase and aromatase activities in pre- and postmenopausal breast cancer patients. Journal of Clinical Endocrinology and Metabolism 81 1460-1464.

Pike MC, Kolonel LN, Henderson BE, Wilkens LR, Hankin JH, Feigelson HS, Wan PC, Stram DO \& Nomura AM 2002 Breast cancer in a multiethnic cohort in Hawaii and Los Angeles: risk factor-adjusted incidence in Japanese equals and in Hawaiians exceeds that in whites. Cancer Epidemiology, Biomarkers and Prevention 11 795-800.

Ranadive GN, Mistry JS, Damodaran K, Khosravi MJ, Diamandi A, Gimpel T, Castracane VD, Patel S \&
Stanczyk FZ 1998 Rapid, convenient radioimmunoassay of estrone sulfate. Clinical Chemistry 44 244-249.

Rinaldi S, Geay A, Dechaud H, Biessy C, ZeleniuchJacquotte A, Akhmedkhanov A, Shore RE, Riboli E, Toniolo P \& Kaaks R 2002 Validity of free testosterone and free estradiol determinations in serum samples from postmenopausal women by theoretical calculations. Cancer Epidemiology, Biomarkers and Prevention 11 1065-1071.

Setiawan VW, Haiman CA, Stanczyk FZ, Le ML \& Henderson BE 2006 Racial/ethnic differences in postmenopausal endogenous hormones: the multiethnic cohort study. Cancer Epidemiology, Biomarkers and Prevention 15 1849-1855.

Shimizu H, Ross RK, Bernstein L, Pike MC \& Henderson BE 1990 Serum oestrogen levels in postmenopausal women: comparison of American whites and Japanese in Japan. British Journal of Cancer 62 451-453.

Sieri S, Krogh V, Bolelli G, Abagnato CA, Grioni S, Pala V, Evangelista A, Allemani C, Micheli A, Tagliabue G et al. 2009 Sex hormone levels, breast cancer risk, and cancer receptor status in postmenopausal women: the ORDET cohort. Cancer Epidemiology, Biomarkers and Prevention 18 169-176.

Sodergard R, Backstrom T, Shanbhag V \& Carstensen H 1982 Calculation of free and bound fractions of testosterone and estradiol-17 $\beta$ to human plasma proteins at body temperature. Journal of Steroid Biochemistry 16 801-810.

Stanczyk FZ, Lee JS \& Santen RJ 2007 Standardization of steroid hormone assays: why, how, and when? Cancer Epidemiology, Biomarkers and Prevention 16 1713-1719.

Stanczyk FZ, Slater CC, Ramos DE, Azen C, Cherala G, Hakala C, Abraham G \& Roy S 2009 Pharmacokinetics of dehydroepiandrosterone and its metabolites after long-term oral dehydroepiandrosterone treatment in postmenopausal women. Menopause 16 272-278.

Toniolo PG, Levitz M, Zeleniuch-Jacquotte A, Banerjee S, Koenig KL, Shore RE, Strax P \& Pasternack BS 1995 A prospective study of endogenous estrogens and breast cancer in postmenopausal women. Journal of the National Cancer Institute 87 190-197.

Tworoger SS \& Hankinson SE 2006 Use of biomarkers in epidemiologic studies: minimizing the influence of measurement error in the study design and analysis. Cancer Causes \& Control 17 889-899.

Vermeulen A, Verdonck L \& Kaufman JM 1999 A critical evaluation of simple methods for the estimation of free testosterone in serum. Journal of Clinical Endocrinology and Metabolism 84 3666-3672.

Wang B, Mi M, Wang J, Wei N, Zhang Q, Zhu J, Yang S, Guo B, Xu J \& Yang X 2009 Does the increase of endogenous steroid hormone levels also affect breast cancer risk in Chinese women? A case-control study in Chongqing, China International Journal of Cancer 124 1892-1899. 
Woolcott CG, Maskarinec G, Pike MC, Henderson BE, Wilkens LR \& Kolonel LN 2009 Breast cancer risk and hysterectomy status: the Multiethnic Cohort study. Cancer Causes and Control 20 539-547.

Wu AH, Yu MC, Tseng CC, Stanczyk FZ \& Pike MC 2009 Dietary patterns and breast cancer risk in Asian American women. American Journal of Clinical Nutrition 89 1145-1154.

Yu H, Shu XO, Shi R, Dai Q, Jin F, Gao YT, Li BD \& Zheng W 2003 Plasma sex steroid hormones and breast cancer risk in Chinese women. International Journal of Cancer 105 92-97.
Zeleniuch-Jacquotte A, Bruning PF, Bonfrer JM, Koenig KL, Shore RE, Kim MY, Pasternack BS \& Toniolo P 1997 Relation of serum levels of testosterone and dehydroepiandrosterone sulfate to risk of breast cancer in postmenopausal women. American Journal of Epidemiology 145 1030-1038.

Zeleniuch-Jacquotte A, Shore RE, Koenig KL, Akhmedkhanov A, Afanasyeva Y, Kato I, Kim MY, Rinaldi S, Kaaks R \& Toniolo P 2004 Postmenopausal levels of oestrogen, androgen, and SHBG and breast cancer: longterm results of a prospective study. British Journal of Cancer 90 153-159. 